\title{
A SPECIFIC REACTION IN ACUTE RHEUMATISM AND RHEUMATOID ARTHRITIS
}

\section{By A. J. MESTER}

THE need for an objective sign or test for the existence or nonexistence of rheumatic infection of joints is of great importance. Researches to this end have been carried out during a period of several years in the First Medical Clinic, Jagellons University, Cracow, Poland. Injection of many different substances-histamine, pilocarpine, atropine, adrenaline, milk, etc. - intracutaneously, subcutaneously and intravenously, were tested by many methods but no specific reaction was identified. Search was made for " $H$ " substances released by strictly regulated skin trauma, but no obvious specific reaction could be detected. Blood was taken from rheumatic and non-rheumatic patients before and after fixed skin trauma. At the height of Lewis's triple response blood was taken from the vein and both injected intramuscularly on the next day- $\mathrm{Si}$, without $\mathrm{H}$ substance and Sii containing $\mathrm{H}$ substance. All the patients were in bed and fasting, and examinations were made for general, local, and blood reactions. It was found that rheumatic patients had a greater production of $H$ substances than the control patients, but thyro-toxic and neurotic patients revealed also an increased production of $\mathrm{H}$ substances.

After prolonged investigations a reaction, however, was found which proved to have a high specificity for rheumatism. This reaction depends on the special sensitivity of rheumatic patients to salicylic acid.

The patients are kept in bed preferably, but ambulatory patients may be examined in the sitting position; in either case they must be fasting. A count is made of the white blood corpuscles, and after this count 1 cubic centimetre of a 0.1 per cent. aqueous solution of salicylic acid is injected intradermally, forming five blebs each of $0.2 \mathrm{c.cm}$. on the flexor aspect of the forearm, and after thirty minutes another white count is made. During this time the patient is forbidden to eat, drink, or make any effort. Nearly all rheumatic patients, acute, subacute or chronic, show after the injection a drop in the number of white cells after thirty minutes; in a further group a second count was made after sixty minutes, but only a small number of rheumatic patients 
showed a drop in the white count after this interval, and these were generally cases in which the infection was of long standing. The lowest figure regarded as positive was 15 per cent. below the level before injection, but diminutions as great as 50 to 70 per cent. were observed. This reaction appears to be positive in every kind of rheumatic infection not only of joints but also of heart, serous membranes, nerves, eyes, etc. In a series of tests 98 per cent. of rheumatic patients gave a positive result, while all controls were negative.

Two cases may be described to demonstrate the value of the reaction. A young woman of 32 years was admitted to the clinic with high temperature, severe arthritis and tachycardia; the spleen was not palpable and only slightly enlarged to percussion, the urine showed a trace of albumin. The electrocardiogram showed a simple tachycardia. The diagnosis lay between acute rheumatic fever and sepsis with joint metastases. The sedimentation rate was over $100 \mathrm{~mm}$. $1 \mathrm{hr}$. Westergren; there was a leucocytosis between 15,000 and 18,000 per cu. mm. and a shift to the left in the Schilling-Arneth count. Blood cultures proved sterile. The salicylic test was negative. Careful search was made for any septic focus without success. At the post mortem ulcerative endocarditis was found, and was evidently the origin of a general septicæmia with joint metastases.

A second case, a woman of 44 years, was admitted with general chronic joint changes of over two years' duration, effusion in both knees and swelling, and deformity of many joints both large and small. The heart and lungs were normal. There was albuminuria 10 to 20 per cent., with hyaline casts, but no lipoids or redblood cells. The blood pressure was low, spleen and lymph glands enlarged. Tests for syphilis in blood and cerebro-spinal fluid were negative. The salicylic reaction was strongly positive. Rheumatoid arthritis with generalised amyloidosis was diagnosed and the post-mortem examination confirmed this; no suppurative process, tuberculosis nor syphilis was discovered. The amyloid degeneration appeared to be solely due to the chronic rheumatic infection.

The test is obviously of service in detecting malingering since rheumatic pains may be complained of and be impossible to disprove by ordinary methods, but the diagnosis must always be relied upon only in conjunction with clinical examination as is the case with all biological tests. For example, a syphilitic patient 
may show joint pains which may be syphilitic or rheumatic, and the test will determine which; the same applies in tuberculosis. The test has been used in several Polish hospitals and found of great service. Professor Lenoch, in the Internal Clinic in Prague, used the test in a hundred and forty cases, and came to the conclusion that it was of great diagnostic value and highly specific.

The salicylic reaction is also of great theoretical importance. It is positive in acute and subacute rheumatic fever and in chronic rheumatoid arthritis. Until now the question of the relationship between rheumatic fever and rheumatoid arthritis has remained open. Some authors are of the opinion that these two diseases are two aspects of the same disease, others think they are two distinct entities. The author is convinced of the relationship between the two and that the link is the "rhumatisme fibreux " of Jaccoud, which is not infrequently met with in France, Poland and Austria.

The immuno-biological skin reactions with streptococcus extracts are in both diseases in the same proportion, positive. The most characteristic product of rheumatic inflammation, the nodules met with in acute and subacute rheumatism, are of the same histological structure as the rheumatic nodules so often seen in rheumatoid arthritis, which are often overlooked because a sufficiently careful search has not been made. The blood findings are also almost identical.

Another problem is the relation between rheumatoid and osteo-arthritis. While peripheral blood and the bone marrow picture in rheumatoid arthritis is inflammatory, osteo-arthritis does not show any blood changes in either the peripheral circulation or the bone marrow. In rheumatoid arthritis the myelogram shows an increased number of plasma cells, reticulum cells and eosinophils, mature and immature, while in osteo-arthritis these cells are normal in number. In osteo-arthritis there is no infective factor, and the author would suggest that a better name would be joint sclerosis in analogy to arterio-sclerosis.

\section{REFERENCES}

BACH: “The Rheumatic Diseases." London, 1935.

LENOCH: Wiener Klin. Wochensch., N. 12, 1938, p. 363.

Mester: Acta Balneologica Polonica, T. 11, N. 25, 1938.

Mester : Polska Gazeta Lekarska, N. 47, 388, 1932. N. 51, 915, 1933.

Tempka: Braun-Folia Homat., N. 48, 355, 1932.

TEMPKA : Kubiczek-Folia Hoemat., N. 60, 18, 1938. 